\title{
Características básicas de la migración guatemalteca al Soconusco chiapaneco*
}

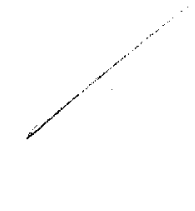

\author{
Manuel Ángel Castillo y Rodolfo Casillas R.**
}

El trabajo contiene una descripción y anáiisis de las principales características detectadas de los trabajadores migratorios temporales guatemaltecos que acuden anualmente a las plantaciones de café de la región del Soconusco en el estado de Chiapas. Se resaltan las precarias condiciones de trabajo y de vida de dicha población en sus lugares de origen, como un referente necesario para comprender la naturaleza y función del trabajo migratorio temporal como parte de los mecanismos de reproducción social de un sector social que vive en condiciones de pobreza:

Los datos utilizados para el análisis fueron obtenidos mediante una encuesta ievantada en la cosecha del ciclo agrícola 1986-1987, en la que se entrevistaron a 591 trabajadores que laboraban en ese momento en 13 unidades productivas de propiedad privada y ejidal, localizadas en los municipios de Tapachula y Unión luárez.

En los últimos tiempos han cobrado importancia en el quehacer académico los distintos fenómenos sociales que se suscitan en la frontera sur de México, en particular los referentes a los diversos flujos migratorios del área centroamericana y su incidencia regional, nacional y de política exterior del Estado mexicano. Uno de los primeros hallazgos del investigador es la escasa información empirica que hay al respecto, pese a que distintas evidencias adelantan la idea de que algunos flujos son de vieja tradición en el sur de México, aparte de los vínculos históricos que existen entre este país y su vecino Guatemala en relación al estado de Chiapas y la región del Soconusco. ${ }^{1}$ Esta falta de conocimiento específico ha alimentado la proliferación de ciertas percepciones equívocas y otras más

* Este artículo contiene una parte de los resultados de la investigación "Impactos regionales de las migraciones internacionales a la frontera sur de México. El caso de los trabajadores estacionales", que en fecha reciente concluyó en su primera fase. Esta investigación se realizó con el copatrocinio de El Colegio de México y el Consejo Nacional de Ciencia y Tecnología.

* * Investigadores del Centro de Estudios Demográficos y de Desarrollo Urbano de El Colegio de México. Dejamos constancia de nuestro reconocimiento a todas las personas e instituciones que han apoyado la realización de este trabajo, en especial, por sus contribuciones en distintas etapas del proyecto a Rosa María Camarena, Emma Calderón D. y Laura Muñoz R.

1 Véase Andrés Fábregas et al., La formación histórica de la frontera sur, en Cuadernos de la Casa Chata 124, Centro de Investigación y Estudios Superiores en Antropología Social, CIESAS, México, 1985, 304 pp.; Antonio Mosquera, Los trabajadores guatemaltecos migrantes a Chiapas, México. Informe Final de Investigación, Area de Ciencias Sociales de la Universidad Autónoma de Chiapas-Asociación Mexicana de Estudios de Población, 1986, mimeo. Juan Pohlenz, Las formaciones de las plantas cafetaleras del Soconusco y el capitalismo en Chiapas, Chiapas, México, 1978, mimeo. Roberto Wasserstrom, "La evolución de la economía regional en Chiapas: 1528-1975”, en América Indígena, México, núm. 36, 1976, pp. 479-498. 
de sentido común, que por limitaciones propias a su naturaleza no explican de manera suficiente el fenómeno migratorio. ${ }^{2}$ Ante esta situación, en el presente artículo nos proponemos contribuir a la caracterización de un tipo específico de migración guatemalteca, con base en la información proporcionada por los mismos migrantes en entrevistas que se realizaron para el efecto. ${ }^{3}$

En este documento nos limitaremos a analizar sólo algunas de las características de la migración laboral que concurre a la cosecha del café en el Soconusco en relación con sus condiciones de vida en su lugar de residencia y que, desde nuestra óptica, determinan las peculiaridades de su migración.

Nuestra tesis fundamental es que los trabajadores migratorios que acuden a las labores de la cosecha del café en las unidades productivas del Soconusco son, en su mayoría, campesinos minifundistas de origen guatemalteco, que proceden del altiplano occidental, y que recurren a la migración temporal como una vía concreta para proveerse de los recursos que les permitan mantener sus niveles mínimos de existencia. También pensamos que de mantenerse las condiciones sociales precarias en el agro guatemalteco, agravadas por el clima de conflicto e inestabilidad sociopolítica en ese país, puede preverse un impacto negativo de ello en este flujo migratorio. ${ }^{4}$

El volumen de la migración temporal: un problema indeterminado

Una preocupación general es cuantificar el flujo migratorio guatemalteco a la frontera sur de México; en particular, interesa saber el quantum de los migrantes laborales. Esto no es fácil de señalar ni de comprobar en el momento actual, dados los limitados conocimientos que se tienen al respecto. En primer lugar, no existen registros oficiales o particulares que pudieran sustentar una aseveración acerca del número y características de los trabajadores migratorios estacionales. Los registros gubernamentales de México son insuficientes porque, según reconocen las propias auto-

2 Véase R. Casillas y M. A. Castillo, "Mitos y realidades de las migraciones centroamericanas a Chiapas", ponencia presentada en el foro "El redescubrimiento de la frontera sur", Universidad Autónoma Metropolitana-Departamento de Etnología y Antropología Social, Instituto Nacional de Antropología e Historia, México, 1987.

${ }^{3}$ Las características metodológicas del procedimiento de la encuesta se encuentran en R. Casillas y M. A. Castillo, Impactos regionales de las migraciones internacionales a la frontera sur de México. El caso de los trabajadores estacionales-Informe técnico final, El Colegio de México-Consejo Nacional de Ciencia y Tecnología, diciembre de 1987, mimeo, especialmente en el capitulo IV.

${ }^{4}$ La situación de conflicto e inestabilidad social en realidad afecta también otros tipos de flujos migratorios. No obstante, para acotar nuestro estudio, aquí sólo mencionamos su eventual impacto en la migración. 
ridades, sólo cubren una proporción indeterminada de los flujos. ${ }^{5}$

La forma como se han realizado las migraciones hasta la fecha impiden documentarla, sobre todo en lo que se refiere a su evolución histórica. En muchos casos se realizan sin ningún registro o control oficial; ello se debe, en parte, a la larga tradición de tránsito que sólo a veces ocurre por escasos puestos fronterizos y, en otros, por una infinidad de veredas o rutas que la costumbre ha establecido, pero sin ninguna posibilidad de instrumentar controles. En todo caso, muchos de los datos existentes dependen de la disposición y buena voluntad de los sujetos directamente involucrados en el fenómeno: migrantes, contratistas, ejidatarios y finqueros.

Otra posible fuente documental es la de los registros de los contratantes y/o contratistas de la mano de obra migrante. Sin embargo, algunos no llevan registros, otros no los proporcionan y otros más ni siquiera permiten el acceso a sus propiedades. ${ }^{6}$ En los centros de investigación académica, por otra parte, apenas si existen trabajos de alcances menores, debido en lo fundamental a los limitados recursos y apoyos financieros con que han contado hasta el presente. ${ }^{7}$ En resumen, la base empíri-

${ }^{5}$ No obstante, diversos voceros oficiales han emitido y emiten constantemente declaraciones acerca del número de trabajadores que llegan anualmente, principalmente a la cosecha del café. En una de las últimas, el delegado regional de la Dirección General de Servicios Migratorios afirmó que para la cosecha de 1987-1988 llegarían 40 mil trabajadores guatemaltecos; en anteriores oportunidades se han mencionado cifras hasta del orden de los 150 mil, pero sin ninguna fundamentación.

${ }^{6}$ Sin embargo, es preciso reconocer que este trabajo fue posible por el apoyo de un grupo de unidades productivas privadas y ejidales (de sus propietarios y empleados recibimos una invalorable y amplia comprensión que facilitó principalmente el acceso a los entrevistados). Asimismo, contamos con la colaboración estrecha de instituciones académicas, así como de dependencias gubernamentales (federales, estatales y municipales) y de personas que facilitaron nuestra labor.

7 Se pueden citar los esfuerzos de algunas instituciones que, en nuestra opinión, han sido los más orgánicos y duraderos: a) el Centro de Investigaciones Ecológicas del Sureste (CIES), en particular investigadores adscritos al Área Socioeconómica, que ha sido fuente de algunos estudios sobre el particular, aunque limitaciones presupuestales han afectado los alcances de sus estudios, así como la difusión amplia y oportuna de los mismos; b) recientemente el CIESAS ha inaugurado una unidad en el sureste, con unos primeros resultados ya en circulación, a algunos de los cuales hace referencia la nota 1 de este artículo; c) la Universidad Nacional Autónoma de México también ha generado un programa en fecha reciente, aún sin productos conocidos; d) algunos investigadores del Área de Ciencias Sociales de la Universidad Autónoma de Chiapas, con apoyos y financiamientos externos, han iniciado una labor pionera, cuyos mejores frutos están todavía por darse; e) en El Colegio de México, aparte de las investigaciones sobre las migraciones centroamericanas y su impacto regional que se realizan en el Centro de Estudios Demográficos y de Desarrollo Urbano, se han efectuado con anterioridad estudios sobre refugiados, seguridad nacional y política exterior de México en el Centro de Estudios Internacionales. Aunque la mayoría de estos distintos esfuerzos pudiera crear una imagen de una gran atención al acontecer en la frontera sur de México, lo cierto es que datan de fecha reciente y, aparte de las limitaciones presupuestales, aún están por establecerse los mecanismos de apoyo e intercambio entre las instituciones mencionadas. Asimismo, habría oue reunir trabajos individuales valiosos. 
ca existente es muy limitada, parcial, difícilmente comparativa y actualizada, con grandes vacíos, tanto en lo que se refiere a los procesos históricos de la migración como a la cobertura de los mismos.

De esa cuenta, tanto las mediciones de la magnitud de las corrientes migratorias como la determinación de sus rasgos particulares, incluyendo su origen social, constituyen una tarea pendiente y difícil de cumplir. Por eso, a continuación presentaremos un primer ensayo de caracterización de un conjunto de trabajadores migratorios a partir de la información captada en las entrevistas realizadas durante la cosecha del café 19861987 en 13 unidades productivas localizadas en los municipios de Tapachula y Unión Juárez del estado de Chiapas. ${ }^{8}$

El altiplano occidental guatemalteco: fuente de mano de obra temporal

Debido al procedimiento seguido en la formulación de los cuestionarios y en el proceso de su aplicación, los 591 trabajadores entrevistados ${ }^{9}$ son de origen guatemalteco - es decir, nacidos en alguna localidad de ese país- y, de las 589 respuestas válidas relativas a la nacionalidad, en su totalidad se trata de guatemaltecos. En ese sentido, $88.5 \%$ son originarios (entendido como lugar de nacimiento) del departamento de San Marcos, la entidad político-administrativa limítrofe con el estado de Chiapas, ubicado en el altiplano occidental de Guatemala. El resto de los entrevistados es originario de 12 de los otros 21 departamentos del país, destacando en niveles subalternos de importancia los procedentes de Quezaltenango con $4.3 \%$, Huehuetenango con $2.4 \%$ y Suchitepéquez con $1.2 \%$; en los demás departamentos se registraron proporciones inferiores a 1\% (cuadro 1).

Por otra parte, el patrón de residencia de los entrevistados es muy semejante al de los lugares de nacimiento, lo cual puede significar una relativa escasa movilidad de carácter permanente. Así, el peso proporcional de los migrantes que viven en el departamento de San Marcos es nuevamente mayoritario (89.2\%) con respecto al de los otros departamentos, ya que el resto de los entrevistados declaró como departamentos de residencia a 14 de los otros $21 \mathrm{y}$, dentro de ellos, los más importantes numéricamente fueron Quezaltenango (4.4\%), Huehuetenango (2.0\%) y Escuintla $(1.2 \%)$, como se ve en el cuadro 2 .

8 Véase la nota 3

9 Debido a los términos en que se establece la contratación de los trabajadores, en su mayoría se trata de hombres; por lo general, las mujeres son acompañantes del trabajador contratado y, en caso de laborar, contribuyentes a las tareas del grupo familiar. Por esa razón, en la encuesta únicamente se entrevistaron a tres mujeres ( $0.51 \%$ del total de cuestionarios), subgrupo que no puede considerarse como representativo de la participación femenina en el universo de trabajadores migratorios temporales. 
CUADRO 1

Lugar de nacimiento de los trabajadores migratorios por departamento y municipio que se indica (en porcentajes)

\begin{tabular}{lcc}
\hline Departamentos y municipios & \% del departamento & \% del total \\
\hline 1) Baja Verapaz & - & 0.2 \\
2) Chimaltenango & - & 0.3 \\
3) Escuintla & - & 0.9 \\
4) Guatemala & - & 0.9 \\
5) Huehuetenango & - & 2.4 \\
6) Jutiapa & - & 0.3 \\
7) Quezaltenango: & - & 2.4 \\
-Coatepeque & 36.0 & - \\
-Colomba & 28.0 & - \\
-Quezaltenango & 12.0 & - \\
8) El Quiché & - & 0.2 \\
9) Retalhuleu & - & 0.3 \\
10) San Marcos: & - & $\mathbf{8 8 . 5}$ \\
-Tacaná & 25.8 & - \\
-Concepción Tutuapa & 14.0 & - \\
-San José Ojetenam & 10.3 & - \\
-Sibinal & 8.1 & - \\
-Tejutla & 6.2 & $\mathbf{0 . 2}$ \\
11) Sololá & - & 1.2 \\
12) Suchitepéquez & - & $\mathbf{0 . 2}$ \\
13) Totonicapán & - & 100.0 \\
Total & - & $(582)$ \\
\hline
\end{tabular}

Fuente: Resultados de las entrevistas del Proyecto "Impactos regionales de las migraciones internacionales a la frontera sur de México. El caso de los trabajadores estacionales". México. El Colegio de México-Conacyt. 1987.

Se observa, a la vez, un esquema de concentración en los municipios de residencia, por cuanto la mayor parte de los entrevistados provenientes del departamento de San Marcos habitaban en los municipios de Tacaná $(22.9 \%)$, Concepción Tutuapa (12.6\%), San José Ojetenam (10.4\%), Sibinal $(7.3 \%)$ y Tejutla (5.9\%); estos municipios alojaban $25.7,14.1,10.4$, 8.2 y $6.6 \%$ de los migrantes que residían en el departamento, mientras que el resto provenía de otros 19 municipios.

La información relativa a los lugares de residencia de los migrantes muestra que la mayor parte procede del departamento de San Marcos y, de ellos, la mayoría se concentra en unos cuantos municipios. Dicho en otras palabras, la procedencia es, mayoritariamente, del altiplano occidental. El intento más elemental de explicación de esta concentración de los lugares de procedencia de los trabajadores tan próxima a la frontera recu- 


\section{CUADRO 2}

Lugar de residencia de los trabajadores migratorios por departamento o estado y municipio que se indica (en porcentajes)

\begin{tabular}{|c|c|c|c|}
\hline $\begin{array}{c}\text { Departamento o estado } y \\
\text { municipio }\end{array}$ & $\%$ por departamento & $\begin{array}{c}\% \text { del total } \\
\text { de residentes } \\
\text { en Guatemala }\end{array}$ & $\begin{array}{l}\% \text { del total } \\
\text { de entrevis } \\
\text { tados }\end{array}$ \\
\hline Baja Verapaz & - & 0.2 & 0.2 \\
\hline Chimaltenango & - & 0.2 & 0.2 \\
\hline Escuintla & - & 1.2 & 1.2 \\
\hline Guatemala & - & 0.3 & 0.3 \\
\hline Huehuetenango & - & 2.0 & 1.9 \\
\hline -Nentón & 18.2 & - & - \\
\hline -San Rafael Petzal & 18.2 & - & - \\
\hline Jutiapa & - & 0.3 & 0.3 \\
\hline Petén & - & 0.2 & 0.2 \\
\hline Quezaltenango & - & 4.4 & 4.3 \\
\hline -Coatepeque & 36.0 & - & - \\
\hline -Colomba & 28.0 & - & - \\
\hline -Quezaltenango & 12.0 & - & - \\
\hline El Quiché & - & 0.2 & 0.2 \\
\hline Retalhuleu & - & 0.3 & 0.3 \\
\hline San Marcos & - & 89.2 & 85.8 \\
\hline -Tacaná & 25.7 & - & - \\
\hline -Concepción Tutuapa & 14.1 & - & - \\
\hline -San José Ojetenam & 10.4 & - & - \\
\hline -Sibinal & 8.2 & - & - \\
\hline -Tejutla & 6.6 & - & - \\
\hline Sololá & - & 0.2 & 0.2 \\
\hline Suchitepéquez & - & 1.1 & 1.0 \\
\hline Totonicapán & - & 0.2 & 0.2 \\
\hline Subtotal & - & - & 96.1 \\
\hline Chiapas & - & - & 3.8 \\
\hline Totales & - & $\begin{array}{l}100.0 \\
(563)\end{array}$ & $\begin{array}{l}100.0 \\
(585)\end{array}$ \\
\hline
\end{tabular}

Fuente: Resultados de las entrevistas del proyecto "Impactos..." (op. cit.).

rriría fácilmente al factor físico. Consideramos que este aspecto es un condicionante importante, mas no fundamental ni único, ${ }^{10}$ y que, en todo caso, en lo que se relaciona con este flujo en particular, aún no se estudia

${ }^{10}$ Los estudios sobre migraciones internas e internacionales en otros ámbitos y situaciones muestran que las distancias a las fuentes de trabajo constituyen un obstáculo relativo y superable por diversas vías. 
con la profundidad debida la compleja red de actividades económicas, comerciales, culturales, etc., que existen entre los asentamientos humanos localizados en uno $u$ otro lado de la frontera México-Guatemala. ${ }^{11}$

Desempleo y subempleo agrícolas: ¿subsistencia posible?

Examinemos ahora las condiciones en que los trabajadores migratorios desarrollan actividades productivas en sus lugares de residencia, es decir, en los que se localizan durante la mayor parte del año. Como en el cuestionario no incluimos preguntas específicas acerca de sus condiciones de vida, ni éstas pudieron ser observadas directamente por la dificultad momentánea de acceder a sus localidades de residencia, ${ }^{12}$ trataremos que los elementos analizados constituyan una base para dar una idea de las posibilidades y condiciones de vida de dichos trabajadores.

El cuestionario indagó la condición de ocupación de los migrantes antes de llegar a los trabajos de la cosecha del café en el Soconusco. En $82.7 \%$ de los casos en que se obtuvieron respuestas válidas, los entrevistados manifestaron haber tenido un trabajo o actividad laboral previa con una duración mayor a una semana (cuadro 3). En el resto, aquellos que no lo hicieron, la principal razón aducida fue "la búsqueda de trabajo sin encontrarlo"' (36.5\%), lo cual permitiría hablar de la difícil situación del agro guatemalteco como generador de empleo, en el marco de una situación de crisis generalizada; ${ }^{13}$ en segundo lugar, la realización de "quehaceres en el hogar" (27.8\%); y en tercero, fue la posesión de un trabajo, "pero por algún motivo no pudo o no fue a trabajar, estuvo enfermo" (20.2\%) (cuadro 4 ).

Aunque sería de esperar que, para la cosecha del café, los trabajadores migrantes fueran todas personas diestras en la labor, cabe precisar que

11 Véase la nota 2.

${ }^{12}$ La dificultad de acceso se debió fundamentalmente a las condiciones de inseguridad que existen en el campo guatemalteco, particularmente para quienes, siendo ajenos a las comunidades alli residentes, se presenten con intenciones de informarse de las condiciones socioeconómicas locales. Esto quedó comprobado incluso en diversos momentos del trabajo de campo realizado en el Soconusco, cuando algunos de los entrevistados se mostraron renuentes a informar sobre sus condiciones de vida en sus lugares habituales de residencia y ante un cierto embarazo colectivo en los momentos de la entrevista.

${ }^{13}$ Alfredo Guerra Borges, Geografía económica de Guatemala, Instituto de Investigaciones Económicas y Sociales, Universidad de San Carlos de Guatemala, Imprenta Universitaria, vol. I. (1a, reed.), 1976. También del mismo autor, "La cuestión agraria, cuestión clave de la crisis en Guatemala", en revista Polémica, núm. 13, enero-febrero de 1984, ICADıs, San José, Costa Rica, pp. 51-57. Por otra parte, hay que notar que el elevado porcentaje de los que declararon haber trabajado incluye a los que realizaron labores en sus reducidas e insuficientes parcelas, como nos proponemos demostrar adelante. 
CUADRO 3

Condición de ocupación de los trabajadores migratorios (en porcentajes)

\begin{tabular}{lc}
\hline Tuvieron trabajo & $\mathbf{8 2 . 7 \%}$ \\
No trabajaron & $17.3 \%$ \\
Total & 100.0 \\
& $(588)$
\end{tabular}

Nota: Se consideraron como ocupados aquellos que declararon haber trabajado o mantenido una actividad laboral con una duración mayor a una semana en el periodo previo a su venida a México.

Fuente: Resultados de las entrevistas del proyecto "Impactos..." (op. cit.).

\section{CUADRO 4}

Motivos de la desocupación y de la inactividad de los trabajadores migratorios que declararon no haber trabajado (en porcentajes)

1. Tenía trabajo, pero por algún motivo no pudo o no fue a

2. Buscó trabajo y no encontró

3. Hizo quehaceres en el hogar

4. Asistió a la escuela

5. Vivió de rentas, intereses u otras ganancias de sus propiedades

6. Incapacitados para trabajar

7. Otras diversas

Fuente: Resultados de las entrevistas del proyecto "Impactos..." (op. cit.).

en las fincas cafetaleras se requiere el trabajo tanto para el corte y tratamiento del grano como para otras tareas diversas en el campo, pero también se necesita efectuar labores de apoyo y mantenimiento a las instalaciones generales; esto es, la realización de actividades que no necesariamente demandan de los trabajadores antecedentes laborales en el agro, pues las tareas que realizan en la cocina, en el manejo de vehículos de carga, en la reparación de instalaciones, etc., abriría también la participación a personas incluso de entornos citadinos.

Vale la aclaración porque, en una situación de crisis como la que se vive en las regiones de procedencia de los trabajadores migratorios y en la que el desempleo es un rasgo importante en la economía guatemalte- 
$\mathrm{ca},{ }^{14}$ se puede esperar un desplazamiento de población de diversas características ocupacionales, dada la alta demanda de empleo en todo el país. No obstante, las respuestas fueron en el sentido de que $97.8 \%$ de los trabajadores se dedicaban a labores agrícolas en sus lugares de procedencia. ${ }^{15}$ Este resultado confirma que, al menos hasta el presente, las necesidades vinculadas a la cosecha del café como las relacionadas con el mantenimiento de las instalaciones de las unidades productivas cafetaleras del Soconusco pueden ser satisfechas por los trabajadores agrícolas del altiplano occidental guatemalteco y, eventualmente, con la mínima participación de trabajadores urbanos en dichas labores.

La información hasta ahora presentada nos da una idea del origen y residencia rural de la gran mayoría de los trabajadores estacionales. Empero, para redondearla, veamos su relación con la tierra y los medios de producción.

En primer lugar, de las respuestas válidas obtenidas sobre la posición en el trabajo principal de los trabajadores agrícolas, únicamente $12.2 \%$ se declaró como peón o jornalero (para efectos del presente estudio, equivalentes netos a trabajador asalariado); $18.2 \%$ como trabajador familiar, y $69.6 \%$ se distribuyó entre las categorías de propietario, comunero, cooperativista y arrendatario, dentro de las cuales la mayor proporción la constituyeron los propietarios con $66.0 \% .^{16}$

El poco peso relativo de la primera categoría, la de jornaleros, confirmaría que los trabajadores que se ocupan en este tipo de trabajo temporal realizan, en su mayor parte, una actividad basada en una extensión de tięrra a la cual acceden en forma directa (propiedad individual, colectiva, o en arrendamiento); es decir, que son pocos los proletarios agrícolas -aquéllos que realizan actividades remuneradas en unidades privadas- que migran a este tipo de trabajo estacional. A pesar de los elementos citados, su presencia dentro del grupo entrevistado podría explicarse, entre otras razones, por:

14 Según CEPAl (Notas para el estudio económico de América Latina y el Caribe, 1986. Guatemala, Doc. LC/Mex/L.52, CEPAL México, agosto de 1987, mimeo., 48 pp.), Guatemala registró niveles de desocupación total ascendentes, de $31.2 \%$ en 1980 a 44.2\% en 1986, debido a un incremento tendencial del desempleo abierto, mientras que el desempleo equivalente osciló alrededor de $30 \%$.

${ }^{15}$ Dadas las limitaciones de espacio, es imposible presentar los cuadros correspondientes a toda la información empírica que utilizamos en este artículo. En consecuencia, hemos optado por anexar solamente los cuadros que contienen la información más significativa $y$, en los demás casos, "vaciar" en forma discursiva otras cuantificaciones, remitiendo al lector al informe técnico final que en diciembre de 1987 presentamos al Consejo Nacional de Ciencia y Tecnología, "Impactos regionales de las migraciones internacionales a la frontera sur de México. El caso de los trabajadores estacionales", op. cit. Véase, entonces, para este caso el cuadro III-9 del anexo correspondiente en el informe citado.

${ }^{16}$ Véase el cuadro III-12 del informe "Impactos..." op.cit., anexo de cuadros. El porcentaje para comunero es de $1.0 \%$; lo mismo para cooperativista y un ligero incremento con respecto a ellos en el caso del arrendatario de $1.6 \%$. 
- la calendarización de los ciclos de los cultivos, que permite su ausencia en determinados momentos en las unidades en donde laboran en forma permanente;

- una desocupación a partîr del último ciclo, sin que ello signifique necesariamente desempleo en la respuesta correspondiente, ya que tal situación no fue contemplada específicamente en el cuestionario;

- la conveniencia coyuntural de un ingreso favorable ante determinadas condiciones temporales como el cambio de moneda, los niveles salariales, otras prestaciones, etcétera.

Veamos ahora algunos de los elementos particulares para cada caso:

\section{La tierra disponible}

Un primer indicador de la situación de los campesinos ${ }^{17}$ es su relación con el recurso fundamental para la producción agrícola: la tierra cultivable. El cuestionario hizo referencia a dos momentos en la actividad productiva: el primero, una declaración de la extensión cultivada en el ciclo inmediatamente anterior a su venida a trabajar a la cosecha del café; el segundo, un intento de cálculo del promedio de la extensión cultivada durante los tres años agrícolas anteriores al momento de la entrevista.

Los resultados obtenidos para ambas interrogantes no difieren mucho $\mathrm{y}$, al menos en términos de la extensión cultivada, confirman la naturaleza minifundista (o debiéramos decir microfundista) de los campesinos migrantes. Si conservadoramente tomamos la segunda de las variables, es decir, la que se refiere al promedio de los últimos tres años, vemos que en $42.1 \%$ de las respuestas pertinentes se manifestó haber cultivado hasta 0.5 hectáreas y que, acumulativamente, $76.6 \%$ dijo haber cultivado $1.0 \%$ hectáreas o menos. El limite máximo considerado en las posibilidades de respuesta equivale a aproximadamente 4.5 hectáreas y más; solamente $2.3 \%$ del total de respuestas declaró haber cultivado una extensión dentro de este margen abierto. ${ }^{18}$

Por otra parte, si cruzamos la variable régimen de propiedad de la tierra con la extensión promedio cultivada durante los últimos tres años (cuadro 5), encontramos en algunos intervalos resultados porcentuales muy semejantes en lo que se refiere a la superficie cultivada para los distintos tipos de propiedad. Así, por ejemplo, en los tres tipos más importantes para los que se obtuvo información (propiedad propia, propiedad fami-

\footnotetext{
17 Llamaremos provisionalmente campesinos al conjunto de trabajadores que no se declararon como asalariados. Incluiremos también, para la mayoría del análisis, al subconjunto que se consideró trabajador familiar, por cuanto muchos de esos casos aportaron información acerca de la unidad productiva, como una muestra de que la propiedad es un patrimonio familiar, aunque los entrevistados no se consideren como directamente propietarios.

${ }^{18}$ Véase el cuadro III-14 del informe "Impactos..." op. cit. , del anexo de cuadros.
} 


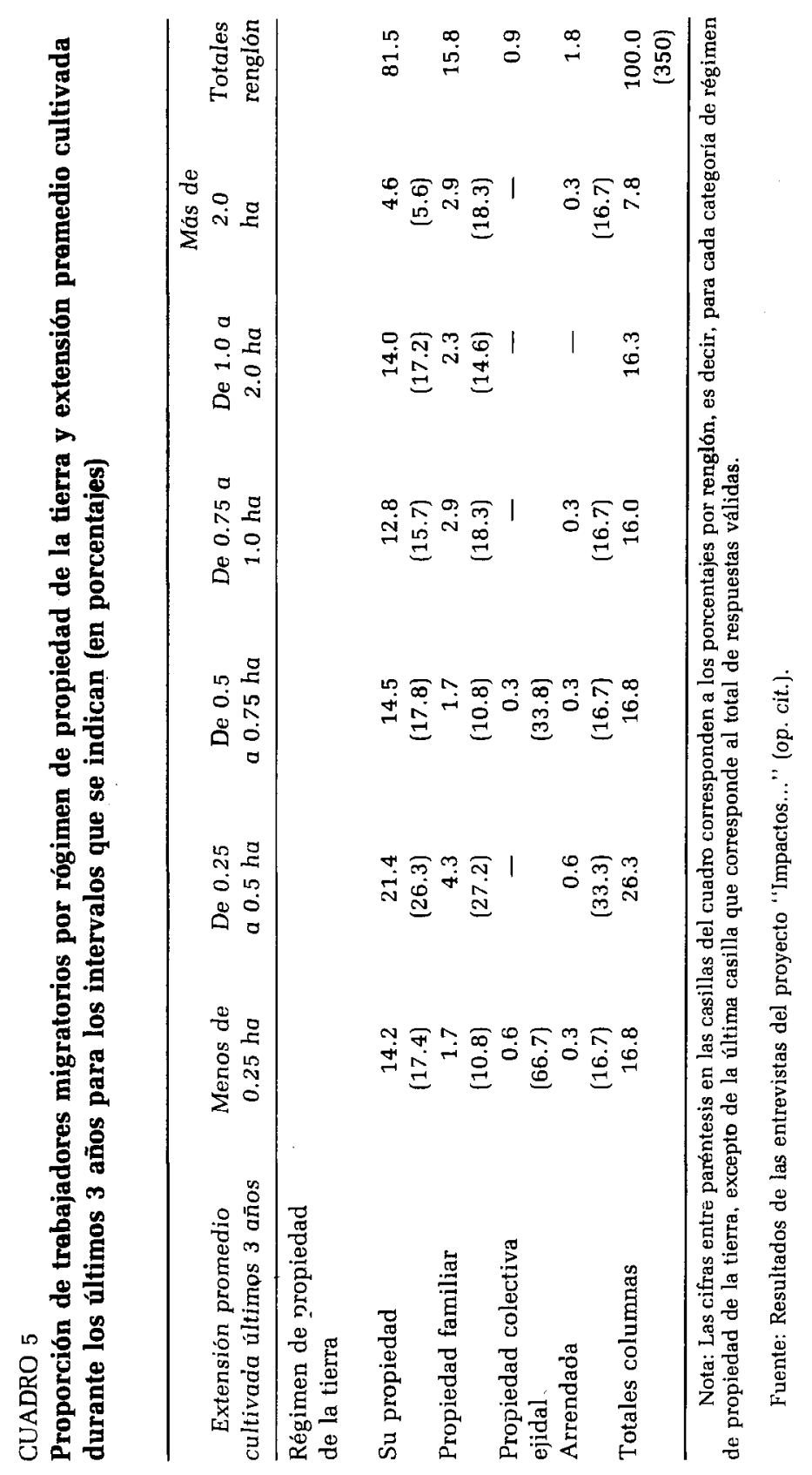


liar y arrendada) y para el total, se observan porcentajes mayoritarios muy próximos de $26.3,27.2,33.3$ y $26.3 \%$ respectivamente para el intervalo de 0.25 a 0.5 hectáreas, lo cual confirma, en otra dimensión, el reducido tamaño de las parcelas sembradas por los trabajadores.

\section{La relación hombre-tierra}

En otro trabajo ${ }^{19}$ hemos argumentado que la relación hombre-tierra, para el caso de los campesinos guatemaltecos, no debe analizarse como una vinculación de carácter estrictamente económico, pues en ella concurren factores de índole cultural, generacional y, en pocas palabras, de identidad. Sin embargo, ello no excluye la importancia de considerar lo referente al aspecto productivo en su acepción amplia: producción para el consumo y para el mercado.

Si partimos del hecho de que las extensiones cultivadas por la mayoría de los declarantes son reducidas, podemos suponer también que la mayor parte de ellas se destina a la producción de bienes de consumo. En tal virtud, el análisis realizado en el inciso anterior es insuficiente, por cuanto encubre situaciones diferenciadas, como el hecho de que el producto de una extensión cultivada puede ser usufructuado por un número más o menos amplio y diverso de personas. Así, puede tratarse tanto de un productor individual como del jefe de una familia nuclear que se sustenta con ella, como también de un trabajador familiar o de un propietario (incluyendo propietarios individuales, colectivos, cooperativistas o arrendatarios) que trabaja un terreno que sirve para la reproducción de una familia extensa.

Sin embargo, con la información disponible no es posible lograr una cuantificación de ese aspecto. Lo que se puede intentar es una aproximación construyendo un indicador, ${ }^{20}$ que permita acercarnos a la relación hombre-tierra. El resultado muestra valores sumamente bajos, como se observa en el cuadro 6. El estándar promedio de 3.5 hectáreas de tierra no regada por familia que propone la Agencia Internacional para el Desarro-

19 Véase "Impactos...", op. cit., pp. 49 y ss.

20 Definimos el indicador tierra cultivada por persona (TCP) como la relación entre el número de dependientes de la tierra, incluyendo al trabajador, al cónyuge (si vive en la misma casa), al número de hijos nacidos vivos y al número de otras personas (además del cónyuge y los hijos) que vivan en la misma casa y la extensión promedio cultivada durante los últimos tres años. Este indicador se apoya en algunos supuestos que es necesario considerar: que la extensión promedio anual cultivada en los últimos tres años corresponde a la extensión realmente cultivable disponible para el trabajador; que el cónyuge conviviente del trabajador también depende para su subsistencia del producto de la tierra cultivada; que todos los hijos nacidos vivos subsisten con base en el producto de la tierra; ello omite el hecho de que algunos ya no viven con el entrevistado por diferentes razones (fallecimiento, emigración, matrimonio, etc.) y, por lo tanto, ya no consumen, ya no se benefician del producto de la parcela, y que las otras personas que conviven con el entrevistado dependen del producto de la tierra cultivada. 
lio, de los Estados Unidos ${ }^{21}$ como mínimo adecuado para la subsistencia familiar, toma en cuenta las diversas situaciones regionales que se pueden encontrar en Guatemala. Si asumiéramos conservadoramente un tamaño promedio de familia campesina de 9 miembros, ${ }^{22}$ el índice TCP -utilizando dicho estándar - sería de 0.4 hectáreas; mientras tanto, según la información recolectada, el TCP máximo alcanzado es de 0.2 hectáreas y a la mayoría (56.6\%) de los declarantes corresponde un indicador inferior a 0.03 hectáreas.

\section{Destino y tipo de producción}

Otra aproximación al carácter de la actividad productiva del campesino es el destino de los cultivos que produce en su propiedad o, en su defecto, de aquella que arrienda. El primer orden de importancia declarado por los entrevistados es que su producción se dirige al consumo familiar (97.2\%), por lo que la producción para el mercado o para el pago de deudas o compras en especie son realmente insignificantes (2.3\% para su venta en el mercado y $0.5 \%$ para el último rubro mencionado). En segundo orden de importancia, la venta en el mercado apenas asciende a $20.8 \%$ del total de declarantes, aunque es mayoritaria (96.1\%) en comparación con la otra posible, que es pago de deudas o compras en especie, con 0.9 y $3.9 \%$ respectivamente. ${ }^{23}$

A reserva de especificar posteriormente las declaraciones de los peones o jornaleros, el tipo de producto predominante en la primera respuesta la constituyen el maíz, frijol o milpa ${ }^{24}$ que, en conjunto, constituyen $65.7 \%$ del total de respuestas válidas; en un segundo orden de importancia representan $37.6 \%$ y, en el tercero, $28.9 \%$. Los cultivos netamente comerciales ${ }^{25}$ solamente constituyen $20.3,7.9$ y $17.1 \%$ de los tres órdenes de importancia respondidos por los entrevistados (cuadro 7).

${ }^{21}$ Agencia Internacional para el Desarrollo: Tierra y trabajo en Guatemala: Una evaluación, Washington, Development Associates, 1982. p. 2.

${ }^{22}$ Por el momento no se cuenta con el tamaño de familia promedio utilizado para la determinación de dicho estándar, pero nueve es un número conservador, puesto que considera los tamaños indirectamente detectados en la encuesta y define una relación menos exigente que la que se establecería con un tamaño promedio menor. cuadros.

${ }^{23}$ Véanse los cuadros III-17 y I11-18 del informe "Impactos..." op.cit., del anexo de

${ }^{24}$ Por milpa se entiende la extensión dedicada al cultivo del maíz y frijol -alimentos básicos de la dieta del campesino- en proporciones no determinadas.

${ }^{25}$ Denominamos "cultivos comerciales" aquellos que no cumplen ninguna función de alimentos de subsistencia y que, en principio, son susceptibles de ser comercializados o intercambiados en el mercado. Esta definición, por supuesto, deja fuera de dicha categoría - por el momento- aquellos productos que forman parte de la dieta básica del campesino, pero que por cualquier razón -incluyendo la constitución de un excedente para las necesidades del productor - , pueden ser comercializados o intercambiados total o parcialmente en el mercado. 


\section{CUADRO 6}

Índice de la tierra per cápita (TCP* en hectáreas per cápita) de los trabajadores migratorios según intervalos que se indican (en porcentajes)

\begin{tabular}{lcc}
\hline Intervalo de TCP & \% del total & \% acumulado \\
\hline 0.01 ha y menos & 8.2 & 8.2 \\
Hasta 0.015 ha & 11.4 & 19.6 \\
Hasta 0.020 ha & 14.6 & 34.2 \\
Hasta 0.025 ha & 11.9 & 46.1 \\
Hasta 0.03 ha & 10.5 & 56.6 \\
Hasta 0.04 ha & 14.2 & 70.8 \\
Hasta 0.05 ha & 9.1 & 79.9 \\
Hasta 0.075 ha & 6.4 & 86.3 \\
Hasta 0.1 ha & 5.9 & 92.2 \\
Hasta 0.2 ha & 7.8 & 100.0 \\
& & $(219)$ \\
\hline
\end{tabular}

* El índice de la tierra cultivada per cápita se calculó de la siguiente manera:

$\mathrm{TCP}=\frac{\mathrm{I}+\text { cónyuge conviviente }+ \text { Núm. de hijos }+ \text { Núm. de otros familiares convivientes }}{\text { Extenslón promedio cultivada últimos } 3 \text { años en ha }}$ Fuente: Resultados de las entrevistas del proyecto "Impactos ..." (op. cit.).

Tipo y grado de acceso a la tierra cultivable

Los resultados muestran que los entrevistados no solamente se consideran a sí mismos mayoritariamente como propietarios de tierra, sino que también en su mayor proporción manifiestan haber laborado, durante el último ciclo agrícola, una parcela propia $(81.5 \%$ de los que respondieron esa pregunta). Si a este subconjunto sumamos la proporción de aquéllos que declararon haber trabajado en una empresa o propiedad familiar $(15.7 \%)$ y en una colectiva $(0.8 \%)$, entendiéndolas como formas de acceso directo a la propiedad, obtenemos $98.0 \%$ del total. El resto se distribuye así: $1.7 \%$ trabajó tierra arrendada y $0.3 \%$ en mediería (es decir, no propia pero que comparte el producto de la cosecha con el propietario) ${ }^{26}$

De los que se declararon propietarios de tierras $(66.0 \%$ del total de respuestas válidas), ${ }^{27}$ prácticamente la totalidad manifestó que la "trabajaba por su cuenta", con excepción de un caso que señaló haberla dado en arrendamiento y trabajado por un salario o jornal en su propia parcela.

\footnotetext{
26 Véase el cuadro III-20 del informe "Impactos..." op. cit., del anexo de cuadros.

27 Véase la nota I1.
} 
CUADRO 7

Importancia relativa de cultivos principales que se señalan del último ciclo agrícola en que participaron los trabajadores migratorios antes de su venida a Mexico de acuerdo a tres órdenes de importancia (en porcentajes)

\begin{tabular}{ccc}
$\begin{array}{c}\text { 1er, orden de } \\
\text { importancia }\end{array}$ & $\begin{array}{c}\text { 2o. orden de } \\
\text { importancia }\end{array}$ & $\begin{array}{c}\text { 3er. orden de } \\
\text { importancia }\end{array}$ \\
\hline
\end{tabular}

a) Tres cultivos básicos o de subsistencia (maíz, frijol y milpa)

b) Cultivos netamente comerciales

c) Resto

(1)

Total

$$
37.6
$$

Nota: La menor magnitud del número de declarantes en el 2o. orden y 3er. orden de importancia se debe en su mayor parte a que dejaron de responderlos, sí habiendo respondido el primero. Ello debe entenderse como la ausencia de otros cultivos adicionales al declarado en el ler. orden de importancia, usualmente uno de los tres básicos. Obsérvese también que en los últimos órdenes de importancia aún se registran porcentajes significativos del ler. grupo de cultivo, lo cual marca una pauta de la importancia de los cultivos de subsistencia.

Las cifras entre paréntesis en las casillas correspondientes a cada uno de los tres tipos de cultivos corresponden a los porcentajes respecto al total de declaraciones, incluyendo aquéllos que no manifestaron otros productos en el 2o. y 3er. orden de importancia.

Fuente: Resultados de la entrevistas del proyecto "Impactos..." (op. cit.).

La segunda mayor frecuencia correspondió al caso de los que se declararon como trabajadores familiares $(18.2 \%)$ y, de ellos, la mayor proporción (93.5\%) manifestó haberlo hecho "a cambio de ayuda en vivienda, comida u otra cosa", lo cual pone de manifesto el tipo de relación predominante no monetaria en el trabajo familiar. ${ }^{28}$

Ya mencionamos que la tercera posición en este apartado la ocupan los peones o jornaleros $(12.1 \%)$, es decir, aquéllos que por falta o insuficiencia de tierras debieron vender su fuerza de trabajo en una unidad productiva que no era de su propiedad. De ellos, $90.2 \%$ se contrataron "en

\footnotetext{
${ }^{28}$ Véase el cuadro III-22 del informe "Impactos..." op. cit., del anexo de cuadros.
} 
una empresa o patrón individual o familiar" y el resto se empleó en una cooperativa de producción. Las otras categorías: arrendatario (1.6\%), comunero y cooperativista ( $1.0 \%$ cada una) son poco significativas en el conjunto, así como en las diferencias que se intentaron establecer en su interior. Probablemente el único aspecto notable es que la gran mayoría de los arrendatarios (81.8\%) manifestó que el pago por la tierra se realizó exclusivamente en dinero y, en menor escala, por pago en especie o eran tomadas en préstamo.

\section{Utilización de mano de obra}

A las preguntas acerca de si habían utilizado algún tipo de mano de obra adicional a la propia, la mayor frecuencia de respuestas correspondió al empleo de familiares no remunerados $(50.0 \%) \mathrm{y}$, dentro de ellos, la mayor proporción correspondió a los que ocuparon dos trabajadores familiares $(33.9 \%)$, como se aprecia en el cuadro 8.

Por otra parte, llama la atención que la segunda mayor frecuencia en este aspecto correspondió al denominado trabajo "mano a mano", que es un sistema de cooperación o intercambio entre vecinos o familiares. La proporción registrada fue de $24.1 \%$. El mayor intercambio se produjo con dos personas $(47.0 \%)$.

La menor frecuencia correspondió, en este estudio, al caso de los trabajadores familiares remunerados $(9.0 \%)$ y, de ellos, la mayor proporción utilizó a dos personas (35.5\%). Dejamos para el final el caso de la contratación de trabajadores asalariados; ésta ocupa la tercera posición con $12.6 \%$ y la mayor proporción utilizó también dos trabajadores (47.7\%).

Puede concluirse entonces que, en general, la utilización de mano de obra adicional a la del trabajador entrevistado es relativamente baja, excepción hecha del caso de trabajadores familiares no remunerados. En dicha categoría encontramos el margen más amplio de respuestas y ello seguramente se explica por el reducido tamaño de las propiedades y la limitada capacidad de inversión de los entrevistados como para obtener apoyos remunerados.

\section{Medios de trabajo}

En este renglón consideramos varios aspectos. En primer término, el uso de herramientas de trabajo. Las respuestas confirmaron el bajo nivel tecnológico empleado y la escasa disponibilidad de instrumentos de trabajo. El primer orden de importancia declarado se refiere al machete, herramienta fundamental y compañera permanente del campesino, pues de las respuestas válidas, $69.1 \%$ la declaró como tal (cuadro 9) y apenas $18.3 \%$ planteó el azadón. Como en el cuestionario se dejó la posibilidad de consignar 


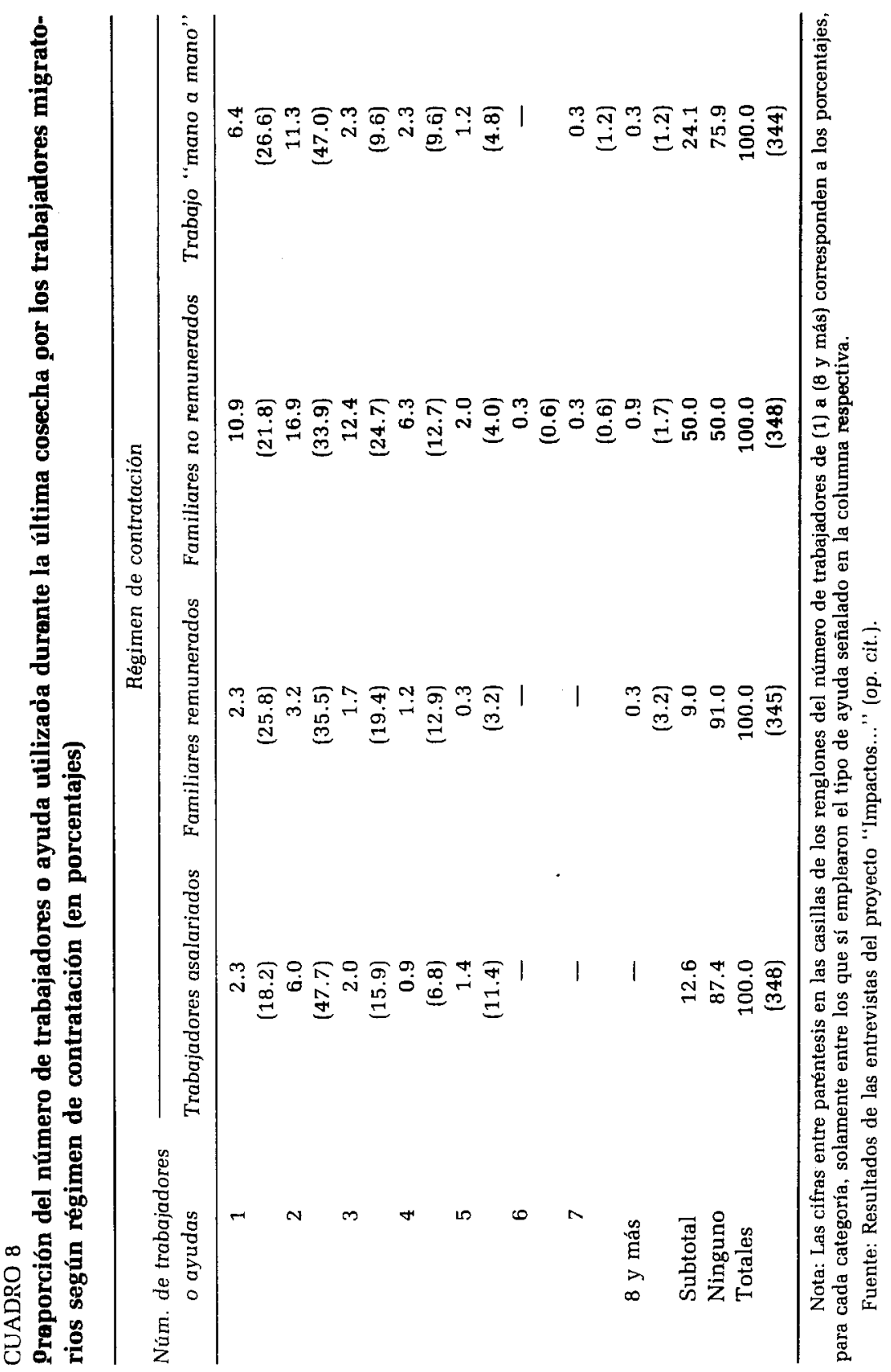


tres herramientas distintas que el trabajador considerara como de uso más común, es interesante notar que el mayor número de frecuencias en el total correspondió precisamente a este último, al azadón, pues del número total de respuestas posibles, esta herramienta acumuló $31.6 \%$, mientras que el machete sólo registró $25.4 \%$. También es importante señalar que, en las respuestas obtenidas, todos los instrumentos de trabajo se refieren a herramientas que utilizan energía humana y, en menor grado, energía animal, pero en ningún caso eléctrica, de combustible, a vapor, etcétera.

Sin embargo, llama la atención que, del total de respuestas posibles acerca de tres insumos para la producción utilizados durante la última cosecha (cuadro 10), la opción que registró el mayor número de frecuencias fueran los fertilizantes químicos, con $25.8 \%$, mientras que los abo-

\section{CUADRO 9}

Proporciones declaradas de utilización de herramientas y maquinaria por los trabajadores migratorios según orden de importancia (en porcentajes)

\begin{tabular}{lcccc}
\hline $\begin{array}{c}\text { Herramienta } \\
\text { maquinaria }\end{array}$ & $\begin{array}{c}\text { 1er. orden } \\
\text { de } \\
\text { importancia }\end{array}$ & $\begin{array}{c}\text { 2o. orden } \\
\text { de } \\
\text { importancia }\end{array}$ & $\begin{array}{c}\text { 3er. orden } \\
\text { de } \\
\text { importancia }\end{array}$ & $\begin{array}{c}\text { \% del total } \\
\text { de respuestas } \\
\text { válidas posibles* }\end{array}$ \\
\hline 1. arado & 10.0 & - & - & 3.3 \\
2. rastra & 0.3 & 0.6 & - & 0.3 \\
3. desgranadora & 1.7 & 0.6 & 0.7 & 0.8 \\
4. machete & 69.1 & 7.5 & 0.7 & 25.4 \\
5. azadón & 18.3 & 77.9 & 12.1 & 31.6 \\
6. yunta de & & & & \\
$\quad$ bueyes & 0.6 & 4.7 & 4.0 & 2.2 \\
7. piocha & - & 7.2 & 48.3 & 9.0 \\
8. coa & - & - & 0.7 & 0.1 \\
9. hacha & - & 0.3 & 16.8 & 2.5 \\
10. cortadora & - & - & 1.3 & 0.2 \\
11. pala & - & - & 0.7 & 0.1 \\
12. lima & - & - & 8.0 & 1.1 \\
13. macana & - & - & 1.3 & 0.2 \\
14. pico & - & 0.6 & 4.7 & 0.9 \\
15. Otros & - & 0.6 & 0.7 & 0.3 \\
Totales & 100.0 & 100.0 & 100.0 & 78.0 \\
& $(350)$ & $(321)$ & $(149)$ & \\
\hline
\end{tabular}

* Incluye la respuesta "ninguna otra" para el 2o. y 3er. orden de importancla, que dan el $22.0 \%$ del total $\left(\begin{array}{ll}1 & 052\end{array}\right)$ de respuestas consideradas.

Fuente: Resultados de las entrevistas del proyecto "Impactos..." (op. cit.). 
nos orgánicos -el segundo lugar en importancia- sólo registraron 24,1\%. Las otras opciones (fungicidas, bactericidas, herbicidas, insecticidas y otras) acumularon proporciones poco significativas, pues hubo un alto porcentaje ( $43.7 \%$ ) de respuestas negativas, es decir, de no uso de insumos, lo cual confirmaría el bajo nivel tecnológico y la limitada capacidad de financiamiento de los campesinos entrevistados.

\section{CUADRO 10}

Proporciones declaradas de utilización de insumos para la producción en la última cosecha de los trabajadores migratorios según orden de importancia (en porcentajes)

\begin{tabular}{lcccc}
\hline \multicolumn{1}{c}{$\begin{array}{c}\text { Insumos } \\
\text { utilizados }\end{array}$} & $\begin{array}{c}\text { 1er. orden } \\
\text { de } \\
\text { importancia }\end{array}$ & $\begin{array}{c}\text { 2o. orden } \\
\text { de } \\
\text { importancia }\end{array}$ & $\begin{array}{c}\text { 3er. orden } \\
\text { de } \\
\text { importancia }\end{array}$ & $\begin{array}{c}\text { \% del total } \\
\text { de respuestas } \\
\text { válidas posibles }\end{array}$ \\
\hline $\begin{array}{l}\text { Fertilizantes } \\
\text { químicos }\end{array}$ & 77.5 & - & - & 25.8 \\
Abonos \\
orgánicos & 17.9 & 54.4 & - & 24.1 \\
Fungicidas & - & 0.6 & 2.0 & 0.8 \\
Bactericidas & - & 0.3 & 1.4 & 0.6 \\
Insecticidas & - & 2.3 & 4.6 & 2.3 \\
Herbicidas & 0.6 & 1.1 & 5.1 & 2.3 \\
Otros & 1.1 & - & - & 0.4 \\
Ninguno & 2.9 & 41.3 & 86.9 & 43.7 \\
Total & 100.0 & 100.0 & 100.0 & 100.0 \\
& $(351)$ & $(351)$ & $(351)$ & $(351)$ \\
\hline
\end{tabular}

Fuente: Resultados de las entrevistas del proyecto "Impactos..." (op. cit.).

La principal fuente de obtención de semillas, de acuerdo a las respuestas obtenidas, es la misma plantación; según ellas, el $80.7 \%$ utilizó sus propios almácigos, en $18.4 \%$ de los casos fueron compradas por el propio trabajador, en $0.3 \%$ fueron obsequiadas por alguna agencia de gobierno, en otro $0.3 \%$ provenían de la comunidad, de una cooperativa o de la familia y, por último, en un tercer $0.3 \%$ provenía de otra fuente. ${ }^{29}$ Los datos obtenidos, en consecuencia, señalan que esta situación también se corresponde con el bajo nivel de desarrollo tecnológico y las limitadas capacidades del minifundio, por cuanto tal dependencia de los reducidos recursos de los propios trabajadores no permite pensar en mejoramiento

${ }^{29}$ Véase el cuadro III-26 del informe "Impactos..." op.cit., del anexo de cuadros. 
y diversificación de variedades, experimentación de plantas, selección de semillas, etcétera.

También las condiciones del agua disponible para regar las parcelas confirman la vulnerabilidad de este tipo de unidad productiva. Solamente $3.9 \%$ dispuso de agua de riego y el total de cuerdas ${ }^{30}$ regadas mediante este recurso fue $2.1 \%$ del total de respuestas, mientras que el resto de productores manifestaron utilizar solamente agua de temporal (lluvias), resultado que se suma a lo reducido de las extensiones, en general, cultivadas por los trabajadores entrevistados. Otro rasgo que confirma esta situación es el que todos los predios que utilizan agua de riego no exceden de 1.5 hectáreas de extensión y, en su mayor parte, son menores de 0.75 hectáreas (cuadro 11).

Finalmente, un último elemento de desventaja en este sentido es la escasa accesibilidad a fuentes de financiamiento. Así, por ejemplo, $96.0 \%$ de las respuestas válidas manifestó que no obtuvo ningún tipo de crédito en los últimos tres años "para los gastos de sus cultivos o de su empresa o negocio". Del resto, $4 \%$, que indicó que sí había utilizado un préstamo para dichos gastos, la mayor proporción -aunque un escaso número absoluto- señaló haberlo recibido de bancos (1.4\%), de cooperativas $(1.1 \%)$, prestamistas particulares $(0.9 \%)$ y de agencias de gobierno y de comerciantes por concepto de anticipos sobre la cosecha con una misma proporción porcentual $(0.3 \%) \cdot{ }^{31}$ Aunque los préstamos bancarios cobran una tasa comercial (no tan elevada como la tasa oficial del sistema bancario mexicano en los últimos años ${ }^{32}$ menor que las usurarias de los particulares y, probablemente, que las que resultan de los anticipos sobre la cosecha, los requisitos que fijan dichas instituciones son difíciles de cumplir. También es muy probable que los montos de los créditos (que no se indagaron en la entrevista) hayan sido muy reducidos, sobre todo si tomamos en cuenta el tamaño de las propiedades que, en todo caso, son la garantía más segura para el otorgamiento de los préstamos bancarios.

El caso de los jornaleros agrícolas

Por el momento nos limitaremos a anotar algunas observaciones respecto a la situación de los trabajadores que declararon haber realizado labores

${ }^{30}$ La cuerda es una medida local de superficie, equivalente a 0.0441 hectáreas.

31 Véase el cuadro III-28 del informe "Impactos..." op.cit., del anexo de cuadros.

32 No consideramos aquí el caso de los bancos agrarios, tanto en uno como en otro país, porque no dispusimos de la información específica acerca de las tasas bancarias ni del tipo de banco a que se estaban refiriendo los informantes. Lo que interesaba señalar es que al momento de la entrevista, las tasas de interés bancario, en condiciones semejantes, son más elevadas en México que en Guatemala y que, aún así, son de difícil acceso para los campesinos entrevistados. 


\section{CUADRO 11}

Proporción del número de unidades productivas y de la extensión de tierra cultivada en la última cosecha por los trabajadores migratorios según tipo de irrigación (temporal y riego) para los intervalos de superficie que se señalan (en porcentajes)

\begin{tabular}{|c|c|c|c|c|}
\hline \multirow[b]{2}{*}{ Extensión cultivada } & \multicolumn{2}{|c|}{ Agua de temporal } & \multicolumn{2}{|c|}{ Agua de riego } \\
\hline & Unidades & Extensión & Unidades & Extensión \\
\hline Hasta 0.25 ha & $\begin{array}{r}14.2 \\
(87.5)\end{array}$ & $\begin{array}{r}3.0 \\
(92.9)\end{array}$ & $\begin{array}{r}50.0 \\
(12.5)\end{array}$ & $\begin{array}{l}10.95 \\
(7.1)\end{array}$ \\
\hline Hasta 0.5 ha & $\begin{array}{r}29.2 \\
(98.1)\end{array}$ & $\begin{array}{r}14.1 \\
(98.5)\end{array}$ & $\begin{array}{l}14.3 \\
(1.9)\end{array}$ & $\begin{array}{l}10.2 \\
(1.5)\end{array}$ \\
\hline Hasta 0.75 ha & $\begin{array}{r}13.9 \\
(98.0)\end{array}$ & $\begin{array}{r}10.5 \\
(97.8)\end{array}$ & $\begin{array}{r}7.1 \\
(2.0)\end{array}$ & $\begin{array}{r}10.5 \\
(2.2)\end{array}$ \\
\hline Hasta $1.0 \mathrm{ha}$ & $\begin{array}{r}17.9 \\
(96.9)\end{array}$ & $\begin{array}{r}18.2 \\
(96.7)\end{array}$ & $\begin{array}{r}14.3 \\
(3.1)\end{array}$ & $\begin{array}{r}29.2 \\
(3.3)\end{array}$ \\
\hline Hasta 1.5 ha & $\begin{array}{r}13.9 \\
(96.0)\end{array}$ & $\begin{array}{r}19.8 \\
(19.8)\end{array}$ & $\begin{array}{r}14.3 \\
(4.0)\end{array}$ & $\begin{array}{r}38.7 \\
(1.1 .2)\end{array}$ \\
\hline Hasta 2.0 ha & 3.2 & 6.5 & - & - \\
\hline Hasta 3.0 ha & 4.6 & 6.5 & - & - \\
\hline Más de 3.0 ha & 3.2 & 15.3 & - & - \\
\hline Totales & $\begin{array}{l}100.0 \\
(346)\end{array}$ & $\begin{array}{r}100.0 \\
(6 \quad 489)^{*}\end{array}$ & $\begin{array}{r}100.0 \\
(14)\end{array}$ & $\begin{array}{r}100.0 \\
(137)^{*}\end{array}$ \\
\hline & $(96.1)$ & $(97.9)$ & $(3.9)$ & $(2.1)$ \\
\hline
\end{tabular}

Nota: Las cifras entre paréntesis en las casillas de cada uno de los intervalos de extensión cultivada, así como las del último renglón de totales, representan la proporción del número de unidades y la extensión cultivada para cada forma de irrigar la tierra en el intervalo respectivo.

* Las extensiones, en términos absolutos, están expresadas en cuerdas, medida local equivalente a 0.0441 hectáreas.

Fuente: Resultados de las entrevistas del proyecto "Impactos..." (op. cit.).

agrícolas contratados como peones o jornaleros. En primer lugar, debemos recordar que, como tales, se declaró $12.1 \%$ de los entrevistados que respondieron a su posición en el trabajo principal. De ellos, $90.2 \%$ indicó que estuvo contratado en una empresa o patrón individual o familiar, mientras que $9.8 \%$ restante lo estuvo en una cooperativa de producción. 
Sin embargo, el punto a dilucidar es el porqué del trabajo migratorio. Es evidente el predominio de la razón "insuficiencia del salario" (83.3\% de las respuestas válidas en cuadro 12), aducida como motivo principal de la migración. Veamos entonces los montos de los salarios promedio diarios y la proporción de trabajadores corespondientes. Del total de entrevistados, $6.9 \%$ señaló un salario promedio diario en el rango Q. 1.00$1.75 ; 20.7 \%$ en el de Q. $2.00-2.75 ; 31.0 \%$ en el de Q. $3.00-3.15 ; 10.0 \%$ en el de Q. 3.20, que es el salario mínimo oficial para el campo en Guatemala; $19.0 \%$ en el de Q. 3.40-4.30; y 12.1\% para el de Q. 4.50-9.00. En conclusión, más de la mitad de los que trabajaron como peones o jornaleros, es decir $58.6 \%$, recibió un ingreso menor al salario mínimo oficial ${ }^{33}$ que, como se sabe, ya de por sí es insuficiente. Por lo tanto, desde este punto de vista, hay una razón de peso para la práctica migratoria como vía complementaria del ingreso necesario para la subsistencia familiar.

Un detalle interesante respecto a este grupo de trabajadores es que $43.1 \%$ de ellos (cuadro 13), que en su mayoría declaró haber laborado para una empresa o patrón individual o familiar, informó que el cultivo principal (como primera prioridad) de la unidad agrícola en que lo hizo era el café, seguido de lejos por el maíz (con $27.6 \%$ ), lo que daría una idea de cierta especialización de la mano de obra y de la posible compatibilidad (que por cierto no podemos afirmar que se haya comprobado en el estudio) entre los periodos de demanda de fuerza de trabajo por parte de las unidades productivas guatemaltecas y mexicanas.

El caso de los trabajadores no agrícolas

Señalamos que sólo una pequeña proporción de los trabajadores que indicaron el tipo de trabajo desarrollado antes de venir a la cosecha del café al Soconusco $(2.2 \%)^{34}$ se encargaba de labores no agrícolas. De ellos, la mayoría trabajó en actividades diversas ( $41.7 \%)$; en fábricas $(33.3 \%)$; en servicios varios (16.7\%), y en actividades comerciales (8.3\%). ${ }^{35}$ En cuanto al régimen de contratación, $54.5 \%$ se desempeñaron como asalariados, $36.4 \%$ como trabajadores por su cuenta (una mitad de ellos se consideraron como propietarios individuales y la otra se integró, en partes iguales, por poseedores de una propiedad familiar y por pertenecientes a una cooperativa) y el restante $9.1 \%$ como trabajadores familiares. ${ }^{36}$

\footnotetext{
33 Véase el cuadro III-30 del informe "Impactos ..." op.cit., del anexo de cuadros. cuadros.

34 Véanse los datos del cuadro HI-9 del informe "Impactos..." op.cit., del anexo de

35 Véase el cuadro III-32 del informe "Impactos ..." op. cit., del anexo de cuadros

36 Véanse los cuadros III-33 y III-34 del informe "Impactos..." op.cit., del anexo de cuadros.
} 


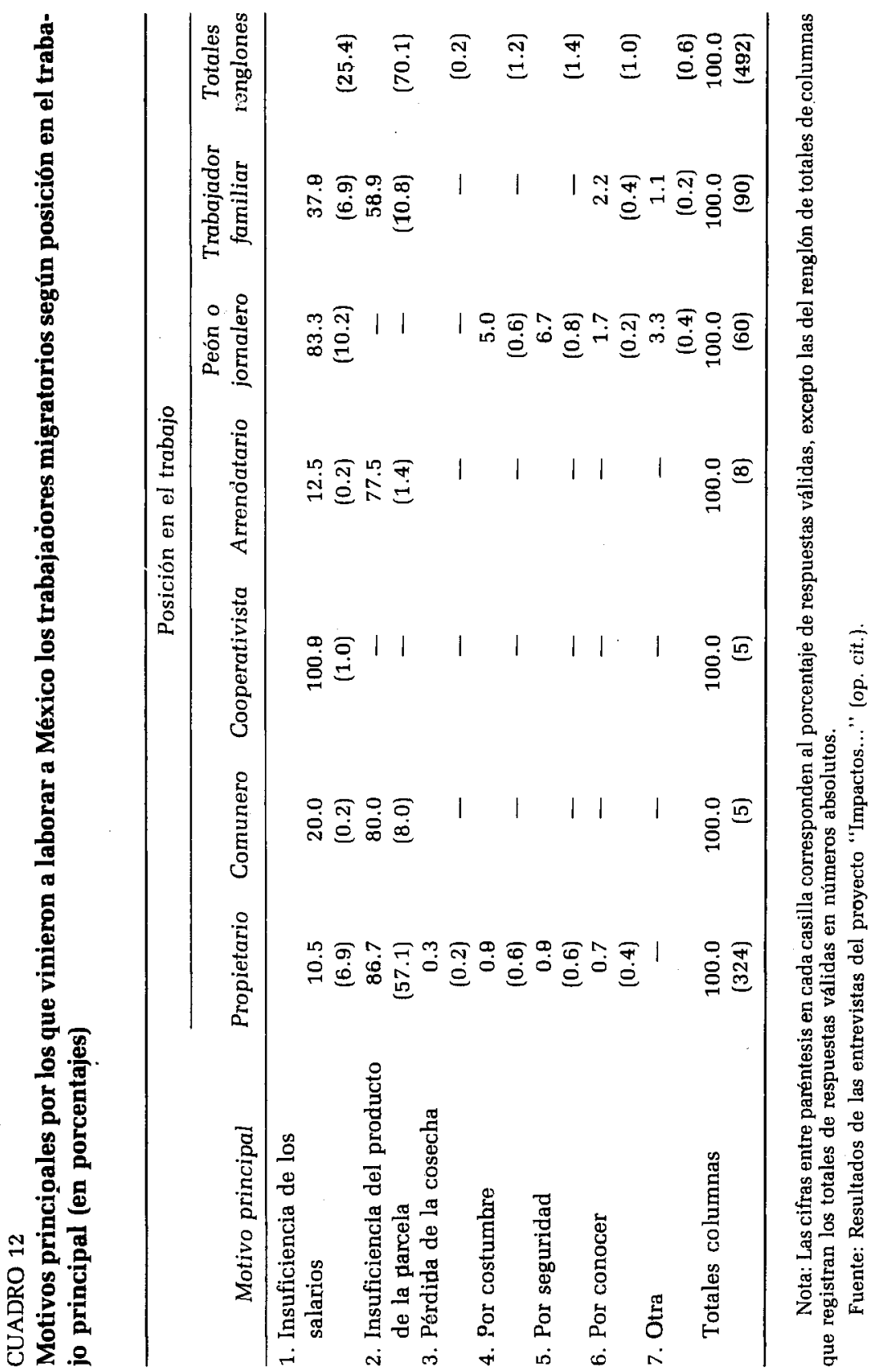


CUADRO 13

Cultivos principales de las unidades agrícolas en que laboran los trabajadores migratorios que se contrataron como peones o jornaleros según orden de importancia (en porcentajes)

\begin{tabular}{|c|c|c|c|}
\hline $\begin{array}{l}\text { Cultivo } \\
\text { principal }\end{array}$ & $\begin{array}{l}\text { 1er. orden de } \\
\text { importancia }\end{array}$ & $\begin{array}{l}\text { 2o. orden de } \\
\text { importancia }\end{array}$ & $\begin{array}{l}\text { 3er. orden de } \\
\text { importancia }\end{array}$ \\
\hline Maíz & 27.6 & 16.6 & 3.0 \\
\hline Frijol & 1.7 & 26.1 & 9.1 \\
\hline Milpa & 6.9 & - & - \\
\hline Ajonjolí & - & 2.4 & 6.1 \\
\hline Arroz & - & 4.8 & 6.1 \\
\hline Café & 43.1 & 2.4 & 6.1 \\
\hline Calabaza & 1.7 & - & - \\
\hline Caña de azúcar & 1.7 & 2.4 & 3.0 \\
\hline Cebada & - & - & 3.0 \\
\hline Cardamomo & - & 2.4 & - \\
\hline Frutales & 1.7 & 4.8 & 12.1 \\
\hline Ganado bovino & 1.7 & - & 3.0 \\
\hline \multicolumn{4}{|l|}{ Ganado ovino o } \\
\hline lanar & - & 2.4 & - \\
\hline Hule & - & - & 3.0 \\
\hline \multicolumn{4}{|l|}{ Legumbres y } \\
\hline Papa & - & 4.8 & - \\
\hline Plátano o banano & 1.7 & 9.5 & 6.1 \\
\hline Yuca & - & - & 3.0 \\
\hline Trigo & - & 4.8 & 15.2 \\
\hline Algodón & - & - & 3.0 \\
\hline \multicolumn{4}{|l|}{$\begin{array}{l}\text { Otras diversas } \\
\text { principalmente } \\
\text { vinculadas al }\end{array}$} \\
\hline café & 12.1 & 16.6 & 12.1 \\
\hline Totales & $\begin{array}{r}100.0 \\
(58)\end{array}$ & $\begin{array}{r}100.0 \\
(42)\end{array}$ & $\begin{array}{r}100.0 \\
(33)\end{array}$ \\
\hline
\end{tabular}

Fuente: Resultados de las entrevistas del proyecto "Impactos..." (op. cit.):

\section{Consideraciones finales}

Como vemos, la información captada permite formarse una idea de las condiciones de existencia y de trabajo de los campesinos guatemaltecos que, en este estudio, mayoritariamente indicaron provenir del altiplano occidental de Guatemala. 
La cercanía del altiplano con el Soconusco chiapaneco es un elemento que incide en la determinación del destino de la migración, aunque no es el único. No obstante, vale precisar que esa cercanía permite que el traslado se realice por caminos vecinales y no necesariamente por los puestos migratorios oficiales; que la migración se componga de núcleos familiares y hasta comunales, y que, en un momento dado, cuando alguno(s) de ellos tiene(n) necesidad de volver, sea(n), en consecuencia, conducto de un sector comunal más amplio y general, que lleve noticias y una porción de los recursos logrados hasta ese momento por la parte migrante a la contraparte familiar y comunal que aguardó en el lugar de residencia. De esta suerte, la cercanía opera como un mecanismo adicional de confiabilidad y seguridad a esos núcleos campesinos, aparte de que contribuye a que durante el periodo de estadía en el Soconusco, los guatemaltecos migrantes puedan reproducir en cierto sentido algunas de sus prácticas socioculturales.

Por otra parte, hemos tratado de demostrar las grandes y graves limitaciones del minifundio guatemalteco, como mínimas extensiones de tierra; mínimas participaciones de insumos e instrumentos que mejoren la productividad; producción fundamental de bienes de autoconsumo, con la consecuente ausencia de producción de bienes para el mercado que, a su vez, provean del dinero necesario para la adquisición de los bienes que necesita el campesino y que no son producidos por él; el agotamiento progresivo de las pequeñas extensiones de tierra que, a su vez, carecen de los tiempos necesarios para su recuperación de manera natural, o bien inducida, por medio de los insumos agrícolas del caso; y la creciente demanda de producción de la tierra ante la multiplicación de la familia o familias que dependen de ella, sin la posibilidad de ensanchar los terrenos de cultivo por falta de recursos propios o crediticios institucionales.

En este sentido, destaca la falta de políticas gubernamentales de asistencia al campesino guatemalteco y de estímulos a la producción, sea para satisfacer la demanda de los propios campesinos, sea para diversificar la producción agrícola en el país.

Ante ello, la migración temporal constituye un recurso prácticamente ineludible para conservar la condición de campesino minifundista y allegarse recursos en dinero. Es muy probable que la situación descrita en el párrafo anterior sea de aplicación común en todo el territorio guatemalteco. Pero no todos los campesinos optan por abandonar definitivamente el campo y enfrentar los avatares de la vida citadina; de hecho, muchas veces esta opción es obligada dada la conflictividad social en el campo, como informan otros estudios sobre la actualidad guatemalteca. En este caso, la información captada permite observar que no obstante el conflicto bélico que los ha azotado, estos campesinos han encontrado la manera de mantener su permanencia en sus tierras de cultivo conjugándola con la práctica de la migración temporal. 
Dada la situación crítica que vive el vecino país en todos los órdenes, no se vislumbran modificaciones sustantivas en torno a la atención y trato a los campesinos y, en general, al agro guatemaltecos. Esto puede significar que los determinantes locales de la migración temporal sigan operando y que la misma se consolide como una vía de escape a las tensiones sociales en el campo guatemalteco. A su vez, las unidades productivas del Soconusco seguramente continuarán requiriendo de la presencia y participación de una fuerza de trabajo que, hasta ahora, ha sido fundamental en la dinámica productiva y, más globalmente, socioeconómica de la región.

En todo caso, hemos planteado solamente una de las partes de un mecanismo de articulación de dos economías agrícolas: una de autoconsumo y otra de producción comercial (la del café, primordialmente orientada a la exportación) ${ }^{37}$ Sin embargo, los datos encontrados muestran que en la de autoconsumo, se mantienen condiciones precarias de vida, así como de acceso a y de uso de los recursos productivos. Para concluir, cabe preguntarse de qué manera la evolución de la crisis én Guatemala puede modificar la situación de la economía campesina de autoconsumo en el altiplano occidental -que requiere de un ingreso complementario para su subsistencia y, por lo tanto, del trabajo migratorio temporal-, lo cual, en cualquier dirección que ocurra, será un factor a considerar en el mercado laboral de la región.

${ }^{37}$ Efectivamente, en el presente trabajo nos concentramos en las condiciones de vida y de trabajo de los migrantes temporales y sus familias en sus lugares de residencia; en un trabajo posterior nos dedicaremos a las condiciones de vida y de trabajo y, en general, a la situación de las unidades productivas que, en el Soconusco, emplean esta fuerza de trabajo temporal. Unas primeras ideas sobre este tópico se incluyen en el informe "Impactos...", op. cit., capítulo IV. 